\title{
Challenges Posed on The New Mining Act and Its Regulations in Tanzania
}

\author{
Charles W. Marwa ${ }^{1} \&$ Isabela Warioba ${ }^{2}$ \\ ${ }^{1}$ Faculty of Law Mzumbe University (LL.B-Mzumbe), LL.M International Laws (MU), Legal consult in \\ Commercial and private law, Tanzania \\ ${ }^{2}$ Head of Department Faculty of Law Mzumbe University (LL.B-Mzumbe), LL.M Human Rights Law (Pretoria), \\ Tanzania \\ Correspondence: Charles W. Marwa, Assistant Lecturer, Faculty of Law Mzumbe University (LL.B-Mzumbe), \\ LL.M International Laws (MU), Legal consult in Commercial and private law, Tanzania. E-mail: \\ charmarwa@gmail.com
}

Received: August 6, 2015 Accepted: August 21, 2015 Online Published: November 29, 2015

doi:10.5539/jpl.v8n4p185 URL: http://dx.doi.org/10.5539/jpl.v8n4p185

\begin{abstract}
This paper assesses the challenges that are posed to the new mining law and other Regulations that govern the mining sector in Tanzania. The main issues discussed in this paper include the conflicts between the local people and the mining companies regarding land ownership, compensation and forced eviction, conflicts between Small Scale Mining (SSM) and Large Scale Mining (LSM).

The findings obtained by the authors, intimates that the major problems in the mining sector are due to lack of law enforcement and good governance in the sector as well as lack of awareness of the laws governing the sector by the local communities.

Lastly, the authors concludes and recommend that, until and unless the laws are adhered to and kept into practice, the problems in the mining sector will not be easily resolved. Hence in order for the mining sector to benefit the indigenous and the investors, there should be enhancement of sustainable development; , people should be educated on the laws and the effects of mining on the environment and the relationship between SSM and LSM be improved.
\end{abstract}

Keywords: new mining act, mining regulation

\section{Introduction}

In 1998, Tanzania enacted the Mining Act $^{1}$ to govern mining activities, the Act worked hand in hand with other legislations and mining regulations to ensure that the environment is not polluted during mining operations, there is transparency and fairness in licensing, that people are fairly compensated as per s .41(4)(d) and 97 of the 2010 Mining Act that requires local communities be properly compensated, relocated and resettled before any mining activities commence; and to stop illegal mining and trading of minerals in the country but all the factors mentioned still encounter obstacles in the sector. And Currently Tanzania has enacted a new Mining Act of 2010 which also addresses how to deal with such recurring problems.

\section{The Meaning of Mining}

Mining is known to be the extraction of valuable minerals or other geological materials from the earth, from an ore body, coal seam. The term also includes the removal of soil. Materials recovered by mining include base metals, precious metals, iron, gold, uranium, coal, diamonds, limestone, rock salt and potash. Mining in a wider sense comprises extraction of any non-renewable resource. Before the mining process starts normally a search is conducted in order to discover the mineral deposits. The process is known as prospecting ${ }^{2}$ or exploration. When

\footnotetext{
1 Mining Act No.5 of 1998

2 'Prospect' is defined by the Mining Act under section 4 as 'the search for any minerals by any means and to carry out any such works and remove such samples as may be necessary to test the mineral bearing qualities of land, and includes the conduct of reconnaissance operations And 'Prospecting area' means an area of land subject to a prospecting licence
} 
a mineral deposit is found, it is studied to determine if it can be mined profitably. If so, the deposit is then worked or extracted by a variety of mining methods.

\section{Mining Methods}

Mining methods are constantly changing and improving as companies forge new technologies to enhance rates of extraction and minimize impacts such as noise, dust, land degradation and water disturbances. There are numerous mining methods utilized around the world including open-cut or open-pit mining (truck-and-shovel, strip mining, quarrying and dragline), underground mining (stooping methods, bord-and-pillar, long wall, caving methods, cut-and-fill and retreat benching) and high wall mining. ${ }^{3}$

In Tanzania the major mining methods in use are open-pit and underground (long hold and drift-and-fill). Variations on these techniques are used depending on the depth and type of the mineral resource.

\section{Enroute to Controversy}

Tanzania being one among the countries whose mining industry is growing, frequently she has been facing conflicts in the Land tenure, this is because of the difference in how land and mineral rights are perceived and this is due to the fact that there is no harmonization between the Land Act and the Mining Act, as a holder of the right of occupancy is not the holder of mineral rights, hence overlapping of the two rights is unavoidable. This in-turn results into conflicts between the two right holders that being the indigenous people who are the owners of right of occupancy and the mining companies that holds mineral rights, leading into eviction of the indigenous from their lands without compensation as per s .41(4)(d) and 97 of the 2010 Mining Act.

Apart from there being various mining regulations and the Mining $\mathrm{Act}^{4}$ that require mining companies to have an environmental management plan before it acquires a mining license, still the mining activities do pose a threat to the environment as communities in the mining areas have had their livelihoods disrupted and their water sources polluted by the large-scale mining. ${ }^{5}$ This can easily entail that the law is not strict enough to enhance environmental protection.

Conflicts between small scale and large scale miners have existed in the mining industry for so many years now, where the coming of foreign gold mining companies have brought a direct contact and confrontation with the indigenous small scale miners over mineral right, the main conflict being because of overlapping of mineral rights where small scale miners do protest against foreign mining companies being given mining rights to areas they claim to have discovered themselves and which they have obtained mining licenses in the past. Further, conflicts rises among them when small scale miners try to attain underground galleries exploited by the Mining Companies illegally by expanding their own galleries several hundred of meters out of the area defined by their mineral right. Hence these forms the sole basis motives of the authors to investigate on the area.

\section{Mining Investment in Tanzania}

Mining investment is of two types, local mining investment and foreign mining investment. Local mining investment is private investment in the mining industry done by Tanzanians; and foreign mining investment can simply be referred to as private investment done by foreigners in the mining industry. Local mining investment is mostly in small scale compared to foreign mining investment.

Mining investments in Tanzania are done through mining development agreements (MDAs) which are governed by the Mining Act. ${ }^{6}$ The Act under section 10(1) empowers the Minister responsible for mining affairs to enter into a MDA with an applicant or a holder of a mineral right. The participants under mining investments are the Government of the United Republic of Tanzania, the investors and the public at large (Agreement should be made with the lawful occupiers of land and their written consent obtained to carry out mining or prospecting operations but in most cases the public tend not to be involved). The investors are of three categories; the large-scale miners, the medium-scale miners, and the small-scale miners.

There are several MDAs entered between the Tanzania government and various mining companies, among them include; East Africa Gold Mine Limited signed in 1999 for the development of North Mara Mine which started production in 2002; Kahama Mining Corporation Limited signed in 1994 for development of the Bulyanhulu Mine which started production in 2001; and East African Mine Limited signed in 1994 for the development of the Buckreef Gold Mine.

\footnotetext{
${ }^{3}$ http://www.nswmin.com.au/Mining-in-NSW/About-the-Industry/How-we-mine/Mining-Methods accessed on (16/07/2014)

${ }^{4}$ Section 44(d) (ii), No. 14 of 2010

${ }^{5}$ B. Kazeri, the Guardian on Sunday, July 31, 2011, Mining Sector: "Victims of wrongful accusations, or guilty as charged?" Pg. 6.

${ }^{6}$ Section 10 of The Mining Act
} 
As provided by section 13 of the Mining Act any holder of mineral right is supposed to abide to the rights and obligation which go in hand with the rights or development agreement entered by him. There are several requirements which an investor in mining sector is expected to fulfill before setting a mining site in Tanzania these requirements can be categorized in three main procedures; ${ }^{7}$

(a) During the entry: Where in this stage the investor has to adhere to the visa requirement and acquire a residence permit as per the Immigration Act. $^{8}$

(b) During the establishment: A mining company should be established according to the Tanzania's Companies Act. ${ }^{9}$

(c) After the establishment: The company has to apply for mineral rights and obtain a mining license according to the Mining Act.

\section{Overview and Analysis of Issues Relating to Mining Sector in Tanzania}

\subsection{Conflicts between Local Communities and Mining Companies}

Many of the conflicts between the local communities and the mining companies do stem from the history of the region; its poverty, its political culture, and the warrior tradition of the people ${ }^{10}$ Sometimes the conflicts erupt because of establishing a mine without securing support of the local community and in turn the indigenous people feel like their land is being stolen from them and they tend to fight back as a means of protecting themselves. Although, most of the mining companies have a mining license to operate the mines but they do lack a social license. ${ }^{11}$ In other words they fail to win the support of the local community which is a crucial requirement for any mining company of recent. ${ }^{12}$

\subsection{Land Ownership}

The right to own land is governed by the Constitution ${ }^{13}$ under Article 24 and The Land Act $^{14}$ respectively. The Latter $^{15}$ divides land into three main categories which are general land, village land and reserve land. The Act further provides that one can own land either by granted right of occupancy or customary right of occupancy which include deemed right of occupancy ${ }^{16}$; village land is acquired through customary right of occupancy ${ }^{17}$ and it's the land used by villagers in support of their livelihood.

The authors learnt that with the current increase of investment in Tanzania there have been numerous cases over land. These cases are based on the conflicts between the local people (villagers) and the investors due to the clash on land ownership by villagers and the use of land by the investors. These conflicts are common in mining areas as most of the mines are found in village land. This has been a problem because most of the investors wish to acquire large pieces of land in various parts of the country resulting into a need of alienating villagers from their land; where in turn leading into conflicts as villagers use the land for their daily earnings such as agricultural activities while investors tend to use it for mining investment.

The authors also found out that in every year there are approximately 1,000 land conflict between villagers and investors. In 2012 1,825 land conflicts were reported and among them 1,095 conflicts involved investors. This is so because land is granted to the investors without involving villagers. ${ }^{18}$ This is mostly common in mining area; where, after the government grants either mining or prospecting license to the investors on the village land, it

\footnotetext{
${ }^{7}$ Rutta. E. R (2009). The Legal Aspects on Foreign Mining Investment and its Economic Impacts in Tanzania

${ }^{8}$ Act No. 7 of 1995 [CAP 54 R.E 2002] which controls immigration issues in Tanzania.

9 [CAP 212 R.E 2002]

${ }^{10}$ Barrick Gold's Tanzania headache: Blood and Stone, Business Times. October 7-13 2011. Pg. 11

${ }^{11}$ Social license can be defined to mean; a comprehensive and thoroughly documented process to have local stakeholders and other vested interests identify their values and beliefs as they participate in scoping the environmental impact assessment of the proposed project and in identifying alternative plans of operations for the project. 'You don't get your social license by going to a government ministry and making an application or simply paying a fee... It requires far more than money to truly become part of the communities in which you operate.' (Pierre Lassonde, President of Newmont Mining Corporation.)

${ }^{12}$ Barrick Gold's Tanzania headache: Blood and Stone, Business Times. October 7-13 2011. Pg. 11.

13 The Constitution of the United Republic of Tanzania of 1977.

${ }^{14}$ Act No. 4 of 1999.

${ }^{15}$ Under section 1(4), Act No. 4 of 1999.

${ }^{16}$ Section 2 of the Village Land Act, Act No. 5 of 1999.

${ }^{17}$ Section 14 of the Village Land Act, Act No. 5 of 1999.

${ }^{18}$ Mamilioni ya Wananchi Afrika Wanaporwa Ardhi. Mwanachi, Jumatano, Machi 7 2012. Pg. 2
} 
finds itself compelled to alienate the villagers from such land to pave way for the investors. ${ }^{19}$ Hence, most of the land rights in mining areas are in the state of uncertainty.

It was also established that; lack of transparency and education on contracts signed between district councils and foreign investors on land has partly contributed to the series of conflicts currently happening across the country. Villagers, who normally become victims of such contracts, give the ecstasy of blame district council authorities for failure to create an equitable balance between their (villagers) interests and the investors' interests. ${ }^{20}$ At the end when villagers realize they are not fairly treated and that they were excluded from decision making on matters which affect them, they start demanding for their rights and that's where the problem begins.

\subsection{Poor Compensation}

A fair and adequate compensation is left to be a dream among the people living in the communities around the mining area. Although both law and practice indicate that once the government has acquire land in respect of granting a mining or prospecting license, it is the duty of a holder of such license to effect compensation, and not only a mere compensation but it should be a fair and adequate compensation.

The Land $\mathrm{Act}^{21}$ provides guidelines to be used in computing compensation, but they have not been kept into practice. Instead unrealistic rates which do not reflect the current economic situation are being used by the valuer in computing compensation. ${ }^{22}$ Also most of the people around the mining area do not know the basic criteria for computing compensation amount for damages for their agricultural land and the crops therein, burial grounds, buildings, destruction of settlement including residential and commercial properties, loss of income or profits generated through employment in small scale mining as well as other costs related to their forceful removal from their settlements. And the whole process is usually unfair as it is done without recourse to legal factors including disturbance, transport and the value of the properties depending on their location. ${ }^{23}$

The following have been the major problems in paying compensation. The process of computing does not involve the villagers rather the mining companies and the government officers. There is no fixed amount of time within which compensation should be paid in turn individuals tends to wait for many years before they are paid. ${ }^{24}$ It has been a practice of the mining companies being granted license over vast of land without taking into consideration if they can actually compensate every one living in the area.

\subsection{Forceful Eviction}

Forced eviction has been defined by the UN habitat as 'the permanent or temporary removal against the will of individuals, families and/or communities from the homes and/or land which they occupy, without the provision of, and access to, appropriate form of legal or other protection. ${ }^{25}$ Forced Evictions are most often characterized by specific decisions, legislation, or policies of States or the failure of States to intervene to halt evictions by non-state actors where as element of force or coercion are often planned, formulated, and announced prior to being carried out. ${ }^{26}$

Among the notable eviction took place in 2001 in Mara region around the mine area of Nyabigena and Nyabirama were villagers were driven away from their lands by an armed police field force Unit (FFU), people were seriously injured during the operation. ${ }^{27}$

\footnotetext{
${ }^{19}$ In 1995, Hon. William Shija (former minister of the ministry of Energy and Minerals) granted a mining Licence No. ML17/96 with respect to Nyabirama area to the East Africa Gold Mining Co. (Africa Mashariki), the land belonged to the villagers who had interest in it; this brought strife between the investors and the local community around the area. See. See. 'Indigenous Peoples' Rights Ignored as Tanzanian Govt Protects Foreign Investors' on http://intercontinentalcry.org .

${ }^{20}$ Land investment should benefit local people. The Guardian, Thursday February 2, 2012. Pg. 7

${ }^{21}$ Section 1(1)(g) of the Land Act, No.4 of 1999;

22 Barrick Gold's Tanzania headache: Blood and Stone, Business Times. October 7-13 2011. Pg. 11.

${ }^{23}$ Madini kwa Maisha; Ujumbe wa Viongozi wa Dini wa Kutafuta Ukweli Kwenye Maeneo ya Migodi. CCT, TEC, BAKWATA. Pg.12. See. Barrick Gold's Tanzania headache: Blood and Stone, Business Times. October 7-13 2011. Pg. 11.

${ }^{24}$ Madini kwa Maisha; Ujumbe wa Viongozi wa Dini wa Kutafuta Ukweli Kwenye Maeneo ya Migodi. CCT, TEC, BAKWATA. Pg.13.

${ }^{25}$ www.unhabitat.org/downloads/docs/10784_1_594339.pdf(12/02/2012)

${ }^{26}$ www.stopvaw.org/definition_of_forced_evictions_3.html (15/01/2012).

${ }^{27}$ LEAT.2003 a Complaint Relating to violation of Fundamental Rights and Duties Arising from Forced Evictions of Artisanal Miners from Africa Mashariki Gold Mine, Tarime.
} 


\subsection{Conflicts between SSM and LSM}

Small-scale miners were the major producers of minerals in Tanzania from 1987 to 1997 and currently approximately 600,000 to $1,000,000$ people are employed in small-scale mining. ${ }^{28}$ The sector often operates outside the ambit of government authority and regulation.

The authors established that, SSM often operate in areas where large mineral deposits are located and after the government discovers the hidden treasure, it grants prospecting or mining license over the area making the SSM to be forced from the concession land and paid inadequate compensation. Worse enough the local community fails to enforce their rights as provided by the Mining Act as the village government and the district council supports the big companies.

SSM have mostly been the victims of forced evictions from the land which is their source of employment, left with no compensation and or any other form of employment to support their families. This has frequently resulted into conflicts over the lands, where as SSM claim to be the founders of the golden treasure which is mostly very true. ${ }^{29}$

Apart from the series of conflicts SSM is faced with the following as challenges: safety problems created by unprotected trenches not rehabilitated and pits left after mining operation has ceased; environmental and health problems caused by the uncontrolled use of reagents used to recover gold; poor recovery of minerals due to use of inadequate techniques for crushing and milling the extracted material; and lack of environmental awareness leading to contamination and pollution of soil, surface and underground water in artisanal and small-scale mining areas. In the Mineral Policy,2009 one of the policy objectives and statements ${ }^{30}$ is to support and develop small scale mining so as to increase its contribution to the economy. This has been so since the last mining law but not much improvement were made and the miners still face the same problems.

\section{Conclusion}

It is seen that, the current mining industry has major developments compared to how it was a decade ago. This is because of the vast investments taking place in the sector favoured by the current laws. Investments are good in generating a country's income, especially the developing ones like Tanzania, but in this case mining investment has over shadowed the people's welfare. The government gives more concern on the investors by making sure that the laws made do favour them, instead of ensuring that they benefit all, both the investors and the people at large.

Experts argue that the government spent more time promoting the country's resource endowment, suitable legal and fiscal regime and the peaceful political environment that could allow private investment thriving. Meanwhile the public at large became spectators as the government was going capitalist entrusting economic means of production to the private sector, the citizens remained socialist praying for the means of production to remain in the hands of public. These two forces were to crush head-on regardless of whether there was success and progress in the reforms or not. ${ }^{31}$

Hence, apart from the government amending the Mining Act and however improved the legal provisions are, unless the present governance challenges are resolved and things addressed in the laws (Mining Act, Land Act, Environmental management Act, Income Tax Act, and Investment Act) are kept into practice the problems of land ownership, compensation, forced eviction, environmental pollution and the conflicts between SSM and LSM won't be solved.

\section{Recommendations}

The authors suggests the following recommendations which are likely to improve or resolve the problems currently faced in the mining sector.

There should be cooperation between the local communities and the mining companies investing in the area as the Mining Act of 2010 stipulates that large and medium scale exploration and mining are open for foreign investment at 100 per cent; local investment at 100 per cent or joint venture at any ratio local/foreign. Land should be used by the local people as a source of income in investment or they should own shares in the

\footnotetext{
${ }^{28}$ Barreto M. L. FORMALIZATION OF ASGM: Is It Possible To Achieve?

${ }^{29}$ Mining Sector: Victim of Wrongful Accusations, or Guilty as Charged? The Guardian on Sunday, July 31, 2011. Pg. 6 \& 8. Also see. RC Supports Villagers in Mine Ownership dispute. The Guardian, Saturday November 5, 2011. Pg. 1 \& 2; Govt Intervenes in Gold-Rich District Dispute. The Guardian, Tuesday March 6, 2012. Pg.1.

${ }^{30}$ The Mineral Policy of Tanzania, 2009. Para 4.0 (f) on Pg. 8. \& Para 5.6 on Pg. 17.

${ }^{31}$ Dr. Dalaly P. Kafumu 'Reforming Tanzania's mining sector' The Citizen Thursday, $29^{\text {th }}$ May 2014 pg.21
} 
investment as remarked earlier. The mining companies should aim at obtaining social license and not only the mineral license, as it is the former which will make their mining activities even more easy as they will have support from the community around the mining area.

The government should ensure that investors do fulfill their obligation under corporate social responsibility over water projects, roads, education, health facilities and electricity in the villages as most of the villagers are desperate, they see precious minerals taken away from their lands without them benefiting.

There should be transparency in contracts signed between our government and the foreign investors. The government should be able to inform the investors that the land they want to acquire for investment is owned by a certain number of villagers who must be compensated fairly as the constitution provides.

The government should also be open to its people. If it intends to grant a certain piece of land to investors, it should inform the individuals occupying the land and even tell them the nature of investment that will take place in the place, how they will be compensated and how they will benefit from such an investment. It should also ensure that before the company is granted mineral rights over an area it has the capacity to compensate fairly all the villagers around the mining area in time in case of any eviction.

The government should fix a certain period of time within which compensation should be paid to the people, as people tend to wait for so many years to be paid and after they are paid the amount given does not reflect the current economic situation they are in.

Land Laws should be kept into practice, especially in the process of computing and effecting compensation. The people should be made aware of the evaluation rates used by the valuer in computing compensation, the things or properties that are subjected to compensation, as most of the indigenous are not aware of the rates and things to be compensated for, hence they end up being cheated and with no knowledge they cannot claim their rights.

The mining laws provide that mining companies should have the relocation and a resettlement plan in case of any eviction. This has to be kept into practice as after eviction most people are left homeless. Therefore, the government should ensure that the plans made when applying for a license are adhered to for the welfare of its people.

The people should be educated on various laws and a regulation governing mining activities, as it is this lack of knowledge which is the source of most of their misunderstandings with the investors. The SSM should also be educated and made aware on the procedure they should take to legalize their mining activities and area by obtaining a mining license over the area, as most of them do mine without having a license.

The government and the investors should involve the people in making decisions on matters that have direct effect on them.

As one of the objectives of the Mineral policy, 2009 the government should ensure that there is cooperation between the SSM and the LSM to avoid the continuing conflicts among them. It should also improve mining methods used by the SSM in order to minimize the environmental impact and enable SSM to contribute to the countries income. Also make sure that abandoned mining sites are rehabilitated and not just left if open pits.

The Ministry responsible should ensure that EIA made by the mining companies before license is grated to them is followed in order to protect the environment for sustainable development. It should also make sure that the mining sites are accessed to ensure that there is no pollution.

\section{Copyrights}

Copyright for this article is retained by the author(s), with first publication rights granted to the journal.

This is an open-access article distributed under the terms and conditions of the Creative Commons Attribution license (http://creativecommons.org/licenses/by/3.0/). 